Vol. XXIII No $3 \quad 2017$

\title{
INFLUENCE OF THE SHOCK WAVE ON THE HYBRID BALLISTIC GELATIN
}

\author{
Ciprian SĂU, Teodora ZECHERU, \\ Claudiu LĂZĂROAIE, Florentina ALEXE
}

\section{Scientific Research Center for CBRN Defense and Ecology, Bucharest, Romania cnsau2002@yahoo.com}

\begin{abstract}
Forensic ballistic tests involve the use of various ballistic gelatins and soaps. Their use is restrained due to several important factors: their synthesis strategy, their availability at room temperature and their rapid degradation even when kept in cold places. The importance of human torso surrogates translates in the facility to verify various ballistic factors impact, such as shock wave or fragments. In the first case, the use of piezoelectric transducers and accelerometers inside torso surrogates helps in defining safety distances and materials for individual protection equipment.
\end{abstract}

Keywords: forensics; materials; ballistics; shock wave.

\section{Introduction}

Human motivation to create and develop materials that provide ballistic protection against bullet impact appeared together with the firearms development. Even from the early stages of development, it was found that the equipment carried by military staff that provided protection against sharpened weapons or other cold weapons are ineffective versus bullet impact.

Nowadays, a wide range of small-caliber firearms that can shoot different types of ammunition for different purposes is encountered. Protection against these threats has constantly improved, and Kevlar ${ }^{\circledR}$ represents the main material that bulletproof vests are made of. Firstly, it was thought that, following a non-piercing impact between bullet and ballistic protection equipment, the human body will not suffer any trauma. After analyzing the level of injury to personnel wearing body armor, following an impact with a nonpiercing bullet, it was found that the occurrence of trauma was not avoided. These traumas are called BABT (Behind Armor Blunt Trauma). The conclusion was that BABT were caused by Back Face Signature (BFS) or bulletproof vest fingerprint, which is the maximum extension of the upper back of the armor when it "catches" the bullet in its fiber layers. Current standards for testing ballistic armor of BFS put a limit not to be exceeded, in order that the equipment be sold.

Thus, BABT is measured as a function of the BFS, accordingly to the standards of ballistic protection equipment testing. Later, it was found that many people have experienced traumas of various intensities, even they were wearing the same type of armor, they were shot with bullets of the same caliber and type, and the bullet did not pierce their armor.

At present, South African Torso Surrogate (SATS) [1] is a human torso surrogate developed in South Africa in order to study BABT caused by the detonation of 
explosives. Versus this SATS, our group developed another human torso surrogate (HTS), in order to estimate the overpressure generated in different points of the human torso, appeared due to the impact of non-piercing bullets and bulletproof vest. This aim is in agreement with the fact that the standards for ballistic testing equipment do not mention issues related to maximum overpressure recordable behind the armor. The main goal is therefore to point out that, in addition to BFS, the overpressure inside the body is an important factor in predicting the BABT severity.

\section{Materials and methods}

HTS has been built to ensure a surrogate that has the ability to simulate tissues and internal organs, mainly those who have cavities in human thoracic and abdominal areas. The construction material is basically a mixture of ballistic gelatin, silicon derivatives and cross-linking agent, since this composite has shown a very good ability to simulate human tissue and torso mechanical properties (Figure 1).

During the manufacturing process, in various locations in the abdomen and chest were attached piezoelectric transducers and accelerometers [2], used to measure the overpressure occurred after shooting.

HTS may also be equipped with a variety of transducers and sensors to monitor various parameters during tests, and the behavior may be recorded using an ultrafast Photron camera.

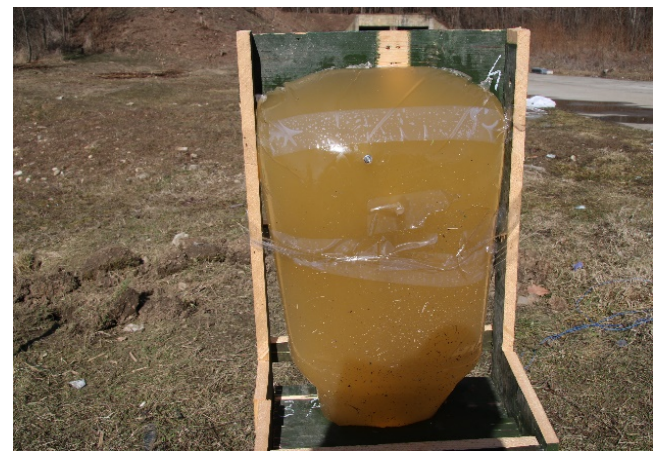

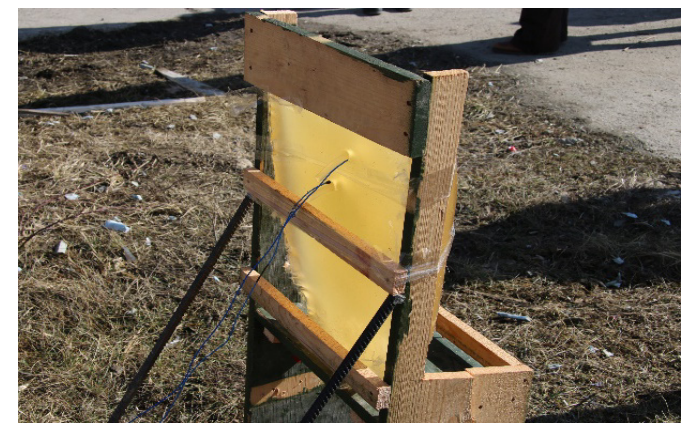

Figure 1. HTS prototype before shooting

\section{Results and discussion}

Most of the experiments that aim to estimate main trauma caused by explosions occurred after the end of the Second World War. Numerous reports, which specified different cases where people died without an apparent cause and without any lesion outside the body led to the conclusion that the factor responsible for these issues is the overpressure in the front of the shock wave, arising from an explosive detonation. Currently, military equipment is equipped with bulletproof vest and helmet, which protect them against different fragments moving at high velocities following an explosion. Thus, the main issue of concern for the armed forces safety is the possibility of survival after the contact with the shock waves, especially under the circumstances of arms and ammunition increasingly more efficient, whose main effect is causing lethality by generating pressure waves and not fragments.

A number of issues related to trauma appearance following exposure to explosion have been emphasized [2-4]. These issues are very important in understanding the phenomenon:

- the dominant effect of the explosion on the body is given by the overpressure in the front of the shock wave;

- the pulmonary edema and the arterial embolism are the major causes 
of death from exposure to the shock wave;

- the overpressure, the duration of exposure and the form of the shock wave conduct to the trauma severity.

Based on this information, Bowen introduced the Bowen curves (Bowen criterion) [5], an empirical model that has as input the peak pressure and the shock wave positive phase. This criterion is still relevant, although it was formulated taking into account the ideal model of the shock waves, which are not reflected. Much later, Bowen curves were modified by Bass [6], who brought changes in shock waves duration of the positive phase of less than $0.5 \mathrm{~ms}$.

Based on simplified mathematical and mechanical models, the Axelsson [7] and Stuhmiller [8-9] criteria were able to link the results obtained to the risk level given by the pressure versus time chart. Axelsson has correlated lethality with the thorax speed during exposure to the shock wave, while Stuhmiller quantified the lethality by defining the normalized mechanical work, as a measure of the amount of energy absorbed by the lung.

Trauma severity assessment method whose use is most prevalent among health professionals is reporting to the AIS scale (Abbreviated Injury Scale), which takes values from 1 , for light trauma, up to 6 , for traumas resulting in a very low probability of survival. It is preferable that the maximum AIS does not exceed 2 in the case of any trauma [10].

In the medical field, every injury corresponds to a certain lethality risk level, depending on severity. To better correlate with severity of trauma, Table 1 shows the connection between the AIS and applied thorax trauma.

\begin{tabular}{|c|c|c|c|}
\hline AIS & $\begin{array}{c}\text { Injury } \\
\text { severity }\end{array}$ & Skeletal injury & $\begin{array}{c}\text { Soft tissue } \\
\text { injury }\end{array}$ \\
\hline 1 & Minor & 1 rib fracture & $\begin{array}{c}\text { Contusion of } \\
\text { bronchus }\end{array}$ \\
\hline 2 & Moderate & $\begin{array}{l}2-3 \text { rib fractures } \\
\text { Sternum fracture }\end{array}$ & $\begin{array}{c}\text { Partial } \\
\text { thickness } \\
\text { bronchus tear }\end{array}$ \\
\hline 3 & Serious & $\begin{array}{c}4 \text { or more rib } \\
\text { fracture on one } \\
\text { side } \\
\text { 2-3 rib fractures } \\
\text { with } \\
\text { hemo/ } \\
\text { pneumothorax }\end{array}$ & $\begin{array}{l}\text { Lung contusion } \\
\text { Minor heart } \\
\text { contusion }\end{array}$ \\
\hline 4 & Severe & $\begin{array}{c}\text { Flail chest } \\
4 \text { or more rib } \\
\text { fractures on each } \\
\text { side } \\
4 \text { or more rib } \\
\text { fractures with } \\
\text { hemo/ } \\
\text { pneumothorax }\end{array}$ & $\begin{array}{l}\text { Bilateral lung } \\
\text { laceration } \\
\text { Minor aortic } \\
\text { laceration } \\
\text { Major heart } \\
\text { contusion }\end{array}$ \\
\hline 5 & Critical & $\begin{array}{c}\text { Bilateral flail } \\
\text { chest }\end{array}$ & $\begin{array}{c}\text { Major aortic } \\
\text { laceration } \\
\text { Lung laceration } \\
\text { with tension } \\
\text { pneumothorax }\end{array}$ \\
\hline 6 & Maximum & & $\begin{array}{c}\text { Aortic } \\
\text { laceration with } \\
\text { haemorrhage } \\
\text { not confined to } \\
\text { mediastinum }\end{array}$ \\
\hline
\end{tabular}

In terms of embedded vital organs, thorax is the most important region of the human body. When it is requested by various forces, displacements and even lesions can occur, affecting both skeletal system and internal organs and tissues.

The main vital organs that are incorporated in the thorax are: heart, lungs, liver and kidneys.

When dealing with a non-piercing impact between the bullet and the armor, it is most likely that non-permanent traumas occur in the thoracic region, such as rib fractures, lung contusions, cardiac injuries, etc.

After the HTS construction, it is desired to 
measure the overpressure occurring to the internal organs, i.e. lungs, heart, liver, and kidneys.

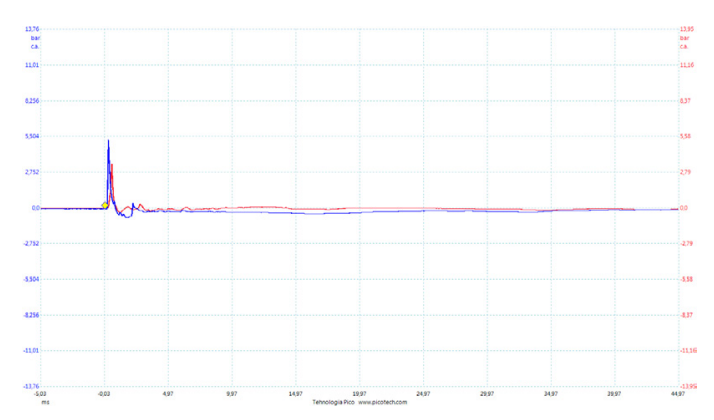

Figure 2. Pressure signals from inside an HTS set $0.5 \mathrm{~m}$ away from an explosion of $100 \mathrm{~g}$ plastic explosive.

The pressure wave, when it encounters a separation surface between two media, is submitted to two types of distortions: a wave reflection and a wave refraction. Thus, the pressure waves will generate a higher pressure amplitude than the incident waves considered by the ideal model of propagation. Since the surrogate has inserts and is made of materials that simulate elasticity and viscosity of the human tissue, the tests will produce results close to the real human body, when exposed to shock waves (Figure 2).

\section{Conclusions and further approach}

Studies conducted to improve staff protection against shock waves generated by explosive detonation mention that the body regions the most affected are the thorax and the engendered organs. Moreover, these parts of the body have great chances to be affected by the pressure waves with the highest amplitude versus other regions, because of numerous hollow components. Pressures recorded in these areas may reach values up to 8 to 10 times higher than the incident pressure that stresses the body.

By mounting transducers for the determination of the incident and reflected pressure occurred to the HTS in the vicinity of various explosion cases, and obtaining the values of the shock waves, may help in evaluating how the shock waves affect the thorax and organs inside. Moreover, this conducts to the obtainment of new and improved materials for ballistic individual protection equipment.

\section{Acknowledgments}

This paper has been supported by a grant of MEN - UEFISCDI under PARTENERIATE program, project no. $307 / 2014$

\section{References}

[1] A.A. Goumtcha, K.Thoral-Pierre, S. Roth, Biomechanical model of the thorax under blast loading: a three dimensional numerical study, International Journal for Numerical Methods in Biomedical Engineering, 30(12), p. 1667-1678, 2014.

[2] Lee, H.J. Sung, Development of an array of pressure sensors with PVDF film, Experiments in Fluids, 26, p. 27-35, 1999.

[3] A.D. Greer, Numerical modeling for the prediction of primary blast injury to the lung, Master Thesis, Canada, 2006.

[4] RTO-TR-HFM-090, Annex H - Supplemental information on overpressure injury assessment, p. H-1-H-12.

[5] I.G. Bowen, E.R. Fletcher, D.R. Richmond, Estimate of man's tolerance to the direct effects of air blast, DASA-2113, p. 1-44, 1968.

[6] C.R. Bass, Injury biomechanics of blast: known and unknown, DSRC Mitigation of blast injury: modeling and simulation workshop, DARPA - Defense Sciences Research Council, Arlington, Virginia, 2005. 
[7] H. Axelsson, J.T. Yelverton, Chest Wall Velocity as a Predictor of Nonauditory Blast Injury in a Complex Wave Environment, The Journal of Trauma, 40(3), 1996.

[8] J.H. Stuhmiller, Y.Y. Phillips III, D.R. Richmond, Chapter 7: The physics and mechanisms of primary blast injury, Conventional Warfare: Ballistic, Blast, and Burn Injuries, p. 241-270.

[9] J.H. Stuhmiller, C.J. Chuong, Y.Y. Philips III, K.T. Dodd, Computer modeling of thoracic response to blast, The Journal of Trauma, 28, p. 132-139, 1988.

[10]K.U. Schmitt, P.F. Niederer, D.S. Cronin, M.H. Muser, F. Walz, Trauma biomechanics: an introduction to injury biomechanics, Springer, 2014. 